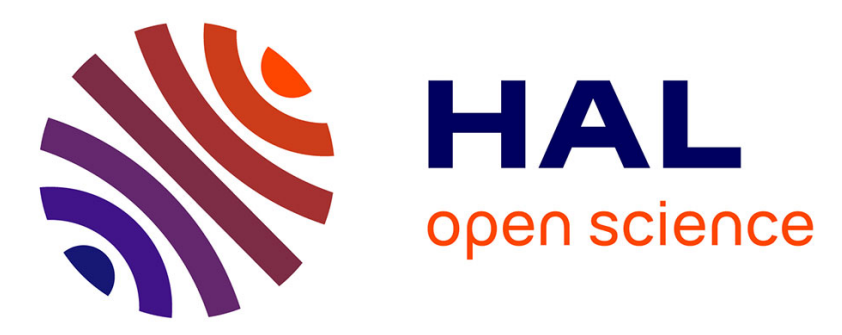

\title{
Water repellency of organic growing media and its consequences on hysteretic behaviours of the water retention curve
}

\author{
R. Naasz, Jean-Charles Michel, Sylvain Charpentier
}

\section{- To cite this version:}

R. Naasz, Jean-Charles Michel, Sylvain Charpentier. Water repellency of organic growing media and its consequences on hysteretic behaviours of the water retention curve. Proceedings of the International Symposium on Growing 2007, Jun 2007, Nottingham (GB), United Kingdom. pp.287-296. hal00730116

\section{HAL Id: hal-00730116}

\section{https://institut-agro-rennes-angers.hal.science/hal-00730116}

Submitted on 5 Apr 2013

HAL is a multi-disciplinary open access archive for the deposit and dissemination of scientific research documents, whether they are published or not. The documents may come from teaching and research institutions in France or abroad, or from public or private research centers.
L'archive ouverte pluridisciplinaire HAL, est destinée au dépôt et à la diffusion de documents scientifiques de niveau recherche, publiés ou non, émanant des établissements d'enseignement et de recherche français ou étrangers, des laboratoires publics ou privés. 


\title{
Water Repellency of Organic Growing Media and Its Consequences on Hysteretic Behaviours of the Water Retention Curve
}

\author{
R. Naasz ${ }^{1,2}$, J.-C. Michel ${ }^{1}$ and S. Charpentier ${ }^{1}$. \\ *Unit A462 \\ ${ }^{1}$ Joint Research Unit 'SAGAH' INRA/INH/Univ. of Angers, 2, rue Le Nôtre, 49045, \\ Angers, France \\ ${ }^{2}$ Department of Soil Science, Univ. Laval, QC, G1K 7P4, Canada
}

Keywords: peat, pine bark, modelling, hydrophobicity

\begin{abstract}
In contrast to soils, most growing media can exhibit hysteresis during drying/ wetting cycles, which greatly affects their hydraulic properties. In the case of organic substrates, hydrophobicity during desiccation could be considered as one of the main factors leading to hysteretic behaviour. The purpose of this study was to estimate the influence of changes in wettability on the water retention properties, $\theta(\psi)$, of peat and pine bark during a drying/wetting cycle. Major differences in the hydraulic behaviour of the two organic materials studied were observed. For peat, hysteresis was found in the water retention curve $(21 \%)$ and also in the contact angle/water potential relationship, $(\alpha(\psi), 20 \%)$, whereas in pine bark, this phenomenon was less pronounced in the water retention curve $(10 \%)$ and even more limited in the $\alpha(\psi)$ curve $(>5 \%)$. Water retention hysteresis was successfully modelled using a modified van GenuchtenDurner approach $\left(V G_{\alpha}\right.$ model), which took into account the local hydrophobicity of each poral domain of the porous media, regardless of the extent of hysteresis. Incorporating the parameters of the $V G_{\alpha}$ water retention model into a $\alpha(\psi)$ equation to characterize overall or average changes in the hydrophobicity of the material during desiccation resulted in values very similar to those of the contact angles calculated with the capillary rise method. These results indicate that water retention properties of these organic substrates are strongly influenced by hydrophobicity.
\end{abstract}

\section{INTRODUCTION}

The hysteresis phenomenon, which depends (a priori) on the hydric history of the soil, has been observed in the $\theta(\psi)$ and $K(\psi)$ curves by some authors (Naasz et al., 2005), but the effect was less pronounced in the $K(\theta)$ curves or was so slight that it was masked by measurement errors and could be ignored.

Although widely observed in soils and horticultural growing media, this phenomenon is still poorly understood and difficult to interpret. Nevertheless, hysteretic behaviour has often been related to one or several of the following specific mechanisms: (1) Non-geometrical uniformity of the pores. This so-called 'ink bottle' effect results from the irregular shape and size of interconnected pores; (2) Presence of trapped air. During the wetting process, part of the gaseous phase can remain trapped in the smallest pores of the material; (3) Shrinkage-swelling phenomena. Many soils and some organic substrates (peats) undergo major volume changes during drying/wetting cycles; and (4) Variation in water repellency. The liquid-solid contact angle varies according to the direction in which the water meniscus moves.

However, studies thus far have failed to clarify the role of individual factors, and hysteresis is still a subject of debate. The hysteretic response is particularly important in horticultural growing media. Organic materials are used preferentially because of their physical qualities but exhibit pronounced hysteretic behaviour (da Silva et al., 1993; Naasz et al., 2005). Moreover, it is well known that organic matter can become markedly hydrophobic depending on water content (Michel et al., 2001), thereby conditioning the physical and hydraulic properties of soils and substrates by inducing rewetting difficulties (Valat et al., 1991) as well as non-uniform wetting and preferential flow. 
In view of these considerations, the motivation of this study was to attempt to estimate the influence of the wettability of two organic substrates on their hysteretic hydraulic properties. The second objective of the study was to formalize this hysteretic response by incorporating the wettability variation into the van Genuchten (1980) water retention model during a drying/wetting cycle.

\section{MATERIALS AND METHODS}

Experiments were carried out on two organic materials that are used for $90 \%$ of growing media production in France and are very widely employed elsewhere: slightly decomposed Sphagnum peat and composted pine bark. The finest fraction of this substrate was used for this study (particle size range of $0-5 \mathrm{~mm}$ ). The main characteristics of peat are presented in Table 1. Since the physical properties of organic substrates are largely influenced by preparation and more precisely by the packing of materials, peat was prepared according to the European standardized procedure.

\section{Water Retention Experiments}

Water retention properties were determined using classical hydrostatical methods. For each of the four replicates, the small cylinders were first placed on the tension table from $-0.3 \mathrm{kPa}$ to $-10 \mathrm{kPa}$. To apply higher suction levels (between $-31.6 \mathrm{kPa}$ and -316 $\mathrm{kPa}$ ), samples were then placed in a pressure-plate apparatus. For the rehydration cycle, samples were placed on a tension table from $-10 \mathrm{kPa}$ to $-0.3 \mathrm{kPa}$, sited with a Mariotte bottle system. Twelve and ten water potential values were used during desiccation and infiltration, respectively.

\section{Wettability Experiments}

In this study, the method based on the capillary rise principle as described by Michel et al. (2001) was used to estimate wettability from contact angle measurements. The capillary rise of various liquids in columns of packed substrate was measured with a Krüss Processor Tensiometer K12 ${ }^{\circledR}$ (Krüss GmbH, Hamburg, Germany). The substrate, at various water potentials, was placed in a glass tube with a porous glass base. The tube was fixed to the microbalance and then placed in contact with a receptacle containing the liquid. The speed of capillary rise was measured in relation to time by computer with the $\mathrm{K} 121^{\circledR}$ program that automatically monitors this tensiometer.

\section{Water Retention and Wettability Modelling}

Van Genuchten (1980) developed a nonlinear function to describe the water retention curve of soils:

$$
\theta(\psi)=\theta_{\mathrm{r}}+\left(\theta_{\mathrm{s}}-\theta_{\mathrm{r}}\right) /\left(1+\left(\alpha_{\mathrm{VG}}|\psi|\right)^{n}\right)^{m}
$$

where $\psi$ represents the pressure head $(\mathrm{m}), \theta$ is the volumetric water content $\left(\mathrm{m}^{3} \mathrm{~m}^{-3}\right), \theta_{\mathrm{r}}$ and $\theta_{\mathrm{s}}$ are the residual volumetric water content and the volumetric water content at saturation $\left(\mathrm{m}^{3} \mathrm{~m}^{-3}\right)$, respectively, $\alpha_{\mathrm{VG}}$ is a curve fitting parameter, also interpreted as the inverse of water potential at the air entry value $\left(1 / \psi_{\mathrm{a}}\right)\left(\mathrm{m}^{-1}\right)$, and $n$ and $m$ are fitting constants that reflect the steepness of the retention curve. To avoid any ambiguity with the contact angle $(\alpha), \alpha_{\mathrm{VG}}$ is replaced by $1 / \psi_{\mathrm{a}}$. The VG model, a function of the actual saturation, $S_{\mathrm{e}}$, becomes:

$$
S_{\mathrm{e}}=\frac{\theta-\theta_{\mathrm{r}}}{\theta_{\mathrm{s}}-\theta_{\mathrm{r}}}=\left(1+\left(\psi / \psi_{\mathrm{a}}\right)^{n}\right)^{-m}
$$

The pore space of the horticultural organic substrates in this study was compartmentalized with respect to water retention. To represent such behaviour, a multimodal porosity approach (Priesack and Durner, 2006) was used assuming that the poresize distribution of structured porous media can be described by a linear superposition of pore-size subsystems (van Genuchten-type subcurves). 
It was also assumed in this study that substrate wettability depends on pore surfaces and can vary according to the pore-size distribution. Consequently, the $\alpha_{\mathrm{i}}$ value, which represents the contact angle of the poral domain $i$, was introduced into the retention expression. The subsequent retention formula, $V G_{\alpha}$, is expressed as follows:

$$
\mathrm{Se}=\sum_{i=1}^{k} w_{\mathrm{i}}\left(1+\left(\psi / \cos \alpha_{\mathrm{i}} \cdot \psi_{\mathrm{ai}}\right)^{n_{\mathrm{i}}}\right)^{-m_{\mathrm{i}}}
$$

Under the assumption that the materials were initially completely wet (at saturation), the $V G_{\alpha}$ model was fitted to retention data during desiccation, with the solidliquid contact angle at $0^{\circ}\left(\cos \alpha_{\mathrm{I}}=1\right)$. During the fitting procedure, all the parameters of the $V G_{\alpha}$ model $\left(\theta_{\mathrm{s}}, \theta_{\mathrm{r}}, \psi_{\mathrm{ai}}, n_{\mathrm{i}}\right.$ and $\left.m_{\mathrm{i}}\right)$ were considered independent coefficients with the following restrictions: $\psi_{\mathrm{a}, \mathrm{i}+1}>\psi_{\mathrm{a}, \mathrm{i}}$ and $\alpha_{\mathrm{i}+1}<\alpha_{\mathrm{i}}$.

By keeping these previously obtained parameters for the adjustment of the $V G_{\alpha}$ model during rehydration, it was assumed that the structure of the material was not deformed during the desiccation-rehydration cycle. In the modified $V G_{\alpha}$ retention function (Equation 3), the contact angle values $\left(\alpha_{\mathrm{i}}\right)$ were then estimated for the best fit between simulations and the observed retention data in the different pore-space fractions of the wetting curve.

Contact angle values were obtained by determining an "average" or apparent contact angle on small samples of substrate in which the pore system was equated to a bundle of capillaries with a mean radius. Using the Washburn approach, the pore space surfaces, $A_{\mathrm{p}}$, could be related to the pore space volume, $V_{\mathrm{p}}$, as follows:

and for the poral domain $i$ :

$$
A_{\mathrm{p}}=\frac{2 V_{\mathrm{p}}}{r}
$$

$$
A_{\mathrm{p}}=\frac{2 w_{\mathrm{i}} S e_{\mathrm{i}} V_{\text {total }}}{r_{\mathrm{i}}}
$$

If it is then assumed that calculated (average) contact angles are proportional to the pore surface that is becoming hydrophobic in the sample, the following equation can be written:

$$
\cos \bar{\alpha}=\frac{\sum_{i} \cos \alpha_{\mathrm{i}} A_{\mathrm{p}, \mathrm{i}}}{\sum_{i} A_{\mathrm{p}, \mathrm{i}}}
$$

where $\bar{\alpha}$ is the average contact angle and $\alpha_{1}$ is the intrinsic contact angle of the poral domain $i$. By using Equation 5 and replacing $r_{\mathrm{i}}$ by the air entry value, $\psi_{\mathrm{a}}$, Equation 6 becomes:

$$
\cos \bar{\alpha}=\frac{\sum_{i} \cos \alpha_{\mathrm{i}} w_{\mathrm{i}} S e_{\mathrm{i}} \psi_{\mathrm{a}, \mathrm{i}}}{\sum_{i} w_{\mathrm{i}} S e_{\mathrm{i}} \psi_{\mathrm{a}, \mathrm{i}}}
$$

where $w_{\mathrm{i}}$ represents the weighting factors, $S_{\mathrm{e}, \mathrm{i}}$ the actual saturation, and $\psi_{\mathrm{ai}}$ the air entry value attributed to the poral domain $i$. All these parameters were previously determined with the $V G_{\alpha}$ model adjustment. Finally, assuming that the pore system is totally hydrophilic $\left(\alpha_{\mathrm{i}}=0^{\circ} ; \cos \alpha_{\mathrm{i}}=1\right)$ when the pore space is full of water and becomes hydrophobic $\left(\alpha_{\mathrm{i}}=90^{\circ} ; \cos \alpha_{\mathrm{i}}=0\right)$ when the pore space is draining, Equation 7 becomes:

$$
\cos \bar{\alpha}(\psi)=\frac{\sum_{i} w_{\mathrm{i}} \psi_{\mathrm{a}, \mathrm{i}} S_{\mathrm{i}}(\psi)}{\sum_{i} w_{\mathrm{i}} \psi_{\mathrm{a}, \mathrm{i}}}
$$




\section{RESULTS AND DISCUSSION}

\section{Retention Properties}

The graphs in Figures 1 and 2 also represent the retention data measured in the $0<$ $\psi<-316 \mathrm{kPa}$ pressure range, interpolated using a unimodal representation of the van Genuchten retention curve ( $V G$-Unimodal) or a multi-modal representation (four poral domains), as proposed by Durner ( $V G$-Multimodal), during drying, and a modified van Genuchten-Durner representation $\left(V G_{\alpha}\right)$ during wetting.

For peat, the unimodal approach failed to adequately describe water retention during desiccation $\left(R^{2}=0.9669\right)$. With the multi-modal approach for peat, the larger number of parameters provided a detailed description of the behaviour of the retention curve near saturation $\left(R^{2}=0.9996\right)$. Such multi-modal behaviour was not evident with the pine bark retention data. Indeed, the unimodal approach ( $V G$-Unimodal) very adequately described the retention data near saturation and at lower water potentials $\left(R^{2}=0.9928\right)$. With the $V G$-Multimodal adjustment, the additional parameters did not lead to a significant increase in the value of the coefficient of determination $\left(R^{2}=0.9987\right)$.

During rehydration, contact angle values $(\alpha)$ were estimated for the best fit between the modified van Genuchten-Durner representation $\left(V G_{\alpha}\right.$, Equation 3$)$ and the observed wetting retention data by keeping all of the other model parameters obtained previously during the drying adjustment (Table 2). For peat, with the unimodal fitting procedure, a contact angle value of $67.03^{\circ}$ was obtained. However, the $V G_{\alpha}$-Unimodal approach did not seem to correctly describe the water retention behaviour of peat during the wetting process (Table 3 ) with a poorer coefficient of determination $\left(R^{2}=0.9613\right)$. On the other hand, the $V G_{\alpha}$-Multimodal approach permitted the adjustment of contact angle values such as water potential and, consequently, the poral domain varied. Estimated contact angle values varied between $90^{\circ}\left(\alpha_{1}\right.$ : at saturation) and $0^{\circ}\left(\alpha_{4}\right.$ : at $\left.-316 \mathrm{kPa}\right)(\mathrm{Table}$ $3)$. Consequently, the coefficient of determination increased considerably $\left(R^{2}=0.9996\right)$ in comparison with the unimodal fitting. For composted bark, both approaches gave very similar adjustments with quasi-equivalent coefficients of determination $\left(R^{2}=0.9954\right.$ and 0.9973 for the unimodal and multi-modal adjustment, respectively; Table 3 ).

\section{Wettability Measurements}

During desiccation, peat showed considerable wettability variation in relation to water potential (Fig. 3). Contact angles varied between $54^{\circ}$ and $80^{\circ}$ for water content values between 0.57 and $0.36 \mathrm{~m}^{3} \mathrm{~m}^{-3}$, in the -3 to $-316 \mathrm{kPa}$ range. During rehydration, and for the same water potential range, contact angles only decreased from $80^{\circ}$ to $67^{\circ}$. As a result, contact angle differences measured during drying compared to rewetting reached $20 \%\left(\Delta \alpha=15^{\circ}\right)$. The wettability of pine bark also varied with water content, but with less amplitude than in peat (Fig. 4). During drying, contact angles only varied between $67^{\circ}$ and $78^{\circ}$ for water content values between 0.48 and $0.38 \mathrm{~m}^{3} \mathrm{~m}^{-3}$. During wetting, the contact angles for pine bark decreased slowly from $78^{\circ}$ to $70^{\circ}$ as water content values varied between 0.38 and $0.41 \mathrm{~m}^{3} \mathrm{~m}^{-3}$. Thus, the wettability of bark during rehydration followed an opposite but similar pattern to that observed during desiccation. Water affinity for bark was nearly the same during both desiccation and rehydration.

\section{Relationships between Hysteretic Properties and Wettability of Substrates}

The elements previously mentioned seem to justify the hydrophobic-hydrophilic explanation for hysteresis. Indeed, the structure of these two organic materials differs greatly. Pine bark is a coarse, platy and non-cohesive material while peat is a fine, fibrous and more cohesive substrate. Draining and filling the bark pore space produces a comparable retention curve, corresponding to a relatively unique poral domain during the drying-wetting experiment. The "average" contact angles calculated with the capillary rise method correspond to the intrinsic ones, estimated with either of the $V G_{\alpha}$ models $\left(V G_{\alpha^{-}}\right.$ Unimodal or $V G_{\alpha}$-Multimodal). When the contact angles simulated with Equation (8) using the parameters of the $V G_{\alpha}$ model are compared to the average calculated contact 
angles, the adjustment is very good, especially for the drying data (Fig. 4). For bark, local hydrophobicity corresponds closely to the sample or total hydrophobicity of the pore space. In peat, smaller pores which remained saturated with water during desiccation retained their pronounced hydrophilic character $\left(\alpha<30^{\circ}\right)$ in all water potential ranges studied. On the other hand, larger pores (corresponding to the poral domain with an equivalent pore diameter between 1600 and $120 \mu \mathrm{m},-0.2 \mathrm{kPa}>\psi>-2.5 \mathrm{kPa}$ ) became highly hydrophobic during desiccation and retained their hydrophobic character during the wetting process $\left(\alpha>82.98^{\circ}\right)$. The contact angles simulated using Equation (8) were also very close to the measured drying data in this case (Fig. 3). The multi-modal water retention pattern is closely associated with the multi-modal hydrophobicity of peat. Although volume changes due to shrinkage/swelling were not measured in this study, such changes could also affect the hydraulic properties, and consequently the hysteretic behaviour, of substrates. The volume of peat can vary as much as 15 to $25 \%$ between the shrinkage and swelling curves, depending on the degree of peat decomposition. Contrary to peat, volume changes in pine bark between the shrinkage and swelling curves were generally less than 10\%. Pine bark exhibited quasi-rigid behaviour, with only small deviations observed during drying compared to wetting.

\section{CONCLUSIONS}

Major differences in the hydraulic behaviour of peat and pine bark were found. Peat showed considerable variation in wettability related to water potential, and considerable hysteresis in contact angle $(20 \%)$ and in the water retention $\theta(\psi)$ curve $(21 \%)$. In contrast, for pine bark, very limited hysteresis was observed in contact angle $(<5 \%)$ and the response was much less pronounced in the $\theta(\psi)$ curve $(10 \%)$. Water retention hysteresis was successfully modelled using a modified van Genuchten-Durner approach $\left(V G_{\alpha}\right.$ model), which took into account the local hydrophobicity of each of the poral domains in both substrates, regardless of the extent of hysteresis. Incorporating the parameters of the $V G_{\alpha}$ water retention model into a $\alpha(\psi)$ equation to characterize overall or average changes in the hydrophobicity of the material during desiccation resulted in values similar to those of the contact angles calculated with the capillary rise method. Volume changes were not measured in this study, but could also affect the hydraulic properties and, consequently, the hysteretic behaviour of the substrates. To confirm the influence of water repellency on this behaviour, further experiments could be carried out on these same materials, but incorporating wetting agents.

\section{Literature Cited}

Charpentier, S., Guérin, V., Morel, P. and Tawegoum, R. 2004. Measuring water content and electrical conductivity in substrates with TDR (Time Domain Reflectometry). Acta Hort. 644:283-290.

da Silva, F.F., Wallach, R. and Chen, Y. 1993. Hydraulic properties of sphagnum peat moss and tuff (scoria) and their potential effects on air availability. Plant Soil. 154:119-126.

Michel, J.C., Riviere, L.M. and Bellon-Fontaine, M.N. 2001. Measurement of the wettability of organic materials in relation to water content by the capillary rise method. European Journal of Soil Science. 52:459-467.

Naasz, R., Michel, J.C. and Charpentier, S. 2005. Measuring Hysteretic Hydraulic Properties of Peat and Pine Bark Using a Transient Method. Soil Sci. Soc. Am. J. 69:13-22.

Priesack, E. and Durner, W. 2006. Closed-form expression for the multi-modal unsaturated conductivity function. Vadose Zone J. 5:121-124.

Valat, B., Jouany, C. and Rivière, L.M. 1991. Characterization of the wetting properties of air-dried peats and composts. Soil Sci. 152:100-107.

Van Genuchten, M.Th. 1980. A closed-form equation for predicting the hydraulic conductivity of unsaturated soils. Soil Sci. Soc. Am. J. 44:892-898. 
$\underline{\text { Tables }}$

Table 1. Main characteristics of the substrates studied. Numbers in parentheses are standard deviations $(n=4)$.

\begin{tabular}{lcccccccc}
\hline Substrates & $\begin{array}{c}\text { Bulk } \\
\text { density } \\
\left(\mathrm{g} \mathrm{cm}^{-3}\right)\end{array}$ & $\begin{array}{c}\text { Particle } \\
\text { density } \\
\left(\mathrm{g} \mathrm{cm}^{-3}\right)\end{array}$ & $\begin{array}{c}\text { Organic } \\
\text { matter } \\
(\%)\end{array}$ & $\begin{array}{c}\mathrm{C} \\
(\%)\end{array}$ & $\begin{array}{c}\mathrm{N} \\
(\%)\end{array}$ & $\begin{array}{c}\mathrm{C} / \mathrm{N} \\
-\end{array}$ & $\begin{array}{c}\mathrm{pH} \\
-\end{array}$ & $\begin{array}{c}\mathrm{CEC} \\
\left(\mathrm{mmol}_{\mathrm{c}} / \mathrm{L}\right)\end{array}$ \\
\hline Peat & 0.119 & 1.53 & 93.0 & 50.5 & 0.932 & 54.2 & 4.4 & 103.1 \\
& $(0.01)$ & $(0.01)$ & $(0.04)$ & $(1.2)$ & $(0.02)$ & - & $(0.04)$ & $(1.1)$ \\
\hline Pine bark & 0.201 & 1.57 & 87.7 & 54.3 & 1.056 & 51.4 & 7.1 & 197.9 \\
& $(0.02)$ & $(0.01)$ & $(0.05)$ & $(6.2)$ & $(0.01)$ & - & $(0.05)$ & $(2.5)$ \\
\hline
\end{tabular}


Table 2. Parameters of the uni- and multi-modal water retention function during drying (VG-Unimodal or VG-Multimodal): fixed values of $\theta_{\mathrm{s}}$; fitted values of $\theta_{\mathrm{r}}, \psi_{\mathrm{a}}, n, m$; and $\alpha=0, \cos \alpha=1$.

\begin{tabular}{|c|c|c|c|c|c|c|c|c|c|c|c|c|c|c|c|c|c|c|c|c|}
\hline \multirow[t]{2}{*}{ Sample } & \multirow{2}{*}{$\begin{array}{l}\text { Poral } \\
\text { domain }\end{array}$} & \multirow{2}{*}{\multicolumn{2}{|c|}{$\begin{array}{l}\theta_{\mathrm{s}} \\
\left(\mathrm{m}^{3} \mathrm{~m}^{-3}\right)^{-\theta_{\mathrm{r}}}\end{array}$}} & \multicolumn{4}{|c|}{ Poral domain 1} & \multicolumn{4}{|c|}{ Poral domain 2} & \multicolumn{4}{|c|}{ Poral domain 3} & \multicolumn{4}{|c|}{ Poral domain 4} & \multirow[b]{2}{*}{$\begin{array}{l}R^{2} \\
-\end{array}$} \\
\hline & & & & $\begin{array}{c}w_{1} \\
-\end{array}$ & $\begin{array}{c}\psi_{\mathrm{a} 1} \\
(-\mathrm{kPa})\end{array}$ & $\begin{array}{c}n_{1} \\
- \\
\end{array}$ & $\begin{array}{c}m_{1} \\
-\end{array}$ & $\begin{array}{c}w_{2} \\
-\end{array}$ & $\begin{array}{c}\psi_{\mathrm{a} 2} \\
(-\mathrm{kPa})\end{array}$ & $\begin{array}{c}n_{2} \\
- \\
\end{array}$ & $m_{2}$ & $\begin{array}{c}w_{3} \\
-\end{array}$ & $\begin{array}{c}\psi_{\mathrm{a} 3} \\
(-\mathrm{kPa}) \\
\end{array}$ & $\begin{array}{c}n_{3} \\
- \\
\end{array}$ & $\begin{array}{c}m_{3} \\
- \\
\end{array}$ & $\begin{array}{c}w_{4} \\
-\end{array}$ & $\begin{array}{c}\psi_{\mathrm{a} 4} \\
(-\mathrm{kPa})\end{array}$ & $\begin{array}{c}n_{4} \\
- \\
\end{array}$ & $\begin{array}{c}m_{4} \\
- \\
\end{array}$ & \\
\hline \multirow[t]{2}{*}{ Peat } & 1 & 0.925 & 0.370 & 1.00 & 3.571 & 0.987 & 99.89 & - & - & - & - & - & - & - & - & - & - & - & - & 0.9669 \\
\hline & 4 & 0.925 & 0.312 & 0.19 & 0.184 & 12.31 & 0.919 & 0.24 & 2.406 & 7.010 & 0.857 & 0.46 & 2.406 & 2.863 & 0.651 & 0.1 & 23.26 & 1.373 & 0.272 & 0.9996 \\
\hline Pine & 1 & 0.862 & 0.386 & 1.00 & 0.204 & 2.418 & 0.341 & - & - & - & - & - & - & - & - & - & - & - & - & 0.9928 \\
\hline bark & 4 & 0.862 & 0.251 & 0.33 & 0.281 & 24.87 & 0.960 & 0.05 & 0.484 & 4.981 & 0.799 & 0.62 & 0.484 & 2.078 & 0.519 & 0.01 & 36.76 & 1.230 & 0.187 & 0.9987 \\
\hline
\end{tabular}

Table 3. Parameters of the uni- and multi-modal water retention function during wetting $\left(\mathrm{VG}_{\alpha}\right)$ : values of $\theta_{\mathrm{s}}, \theta_{\mathrm{r}}, \psi_{\mathrm{a}}, n, m$ correspond to those used during the drying fitting; values of $\alpha$ were fitted.

\begin{tabular}{lccc}
\hline Sample & Poral domain & $\begin{array}{c}\alpha_{\mathrm{i}} \\
\left({ }^{\circ}\right.\end{array}$ & $\begin{array}{c}R^{2} \\
-\end{array}$ \\
\hline Peat & 1 & 67.03 & 0.9613 \\
& 4 & $90-82.98-50.67-0$ & 0.9996 \\
\hline Pine bark & 1 & 60.98 & 0.9954 \\
& 4 & $90-75.69-62.11-0$ & 0.9973 \\
\hline
\end{tabular}




\section{Figures}

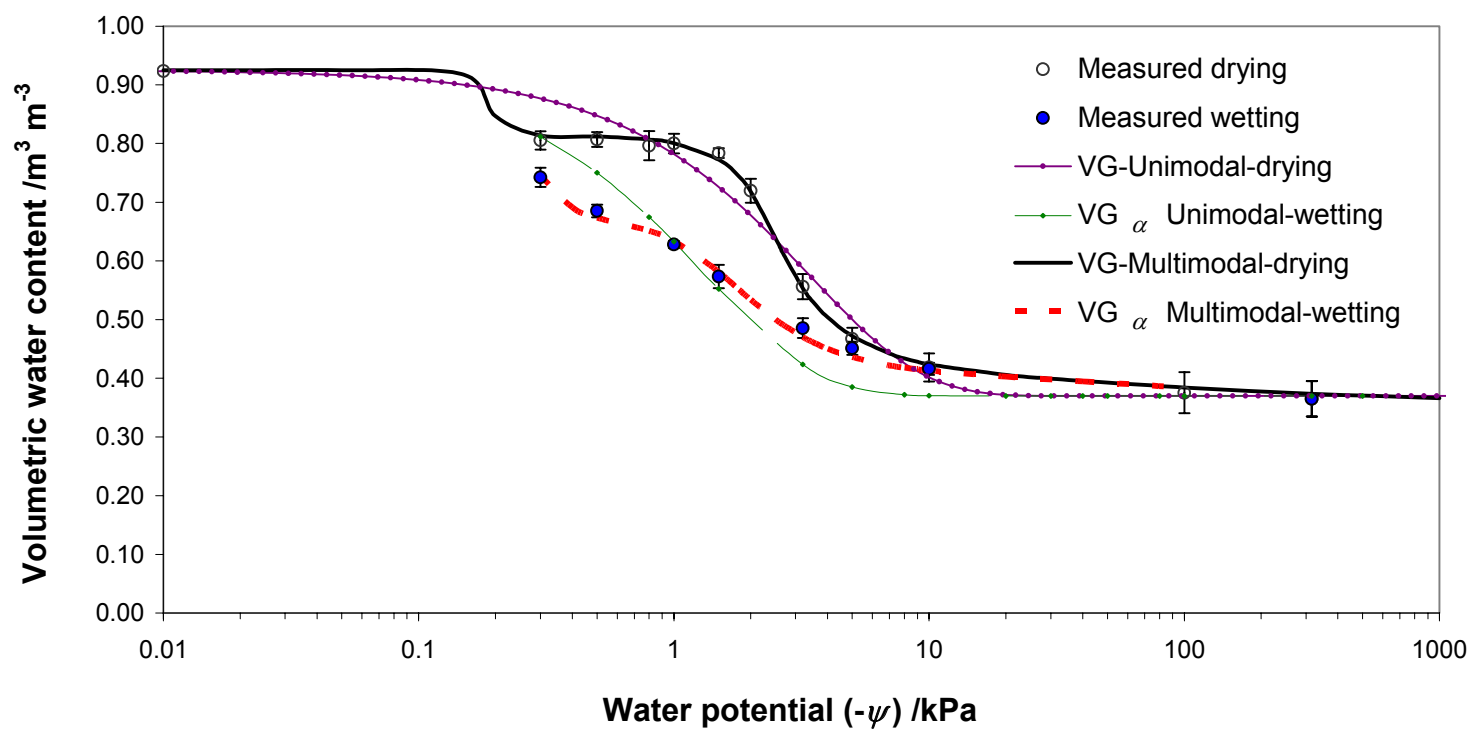

Fig. 1. Measured (symbols) and fitted (VG) water retention curves during drying (VG model) and wetting $\left(\mathrm{VG}_{\alpha}\right.$ model $)$ for peat. The bars indicate standard errors $(n=4)$.

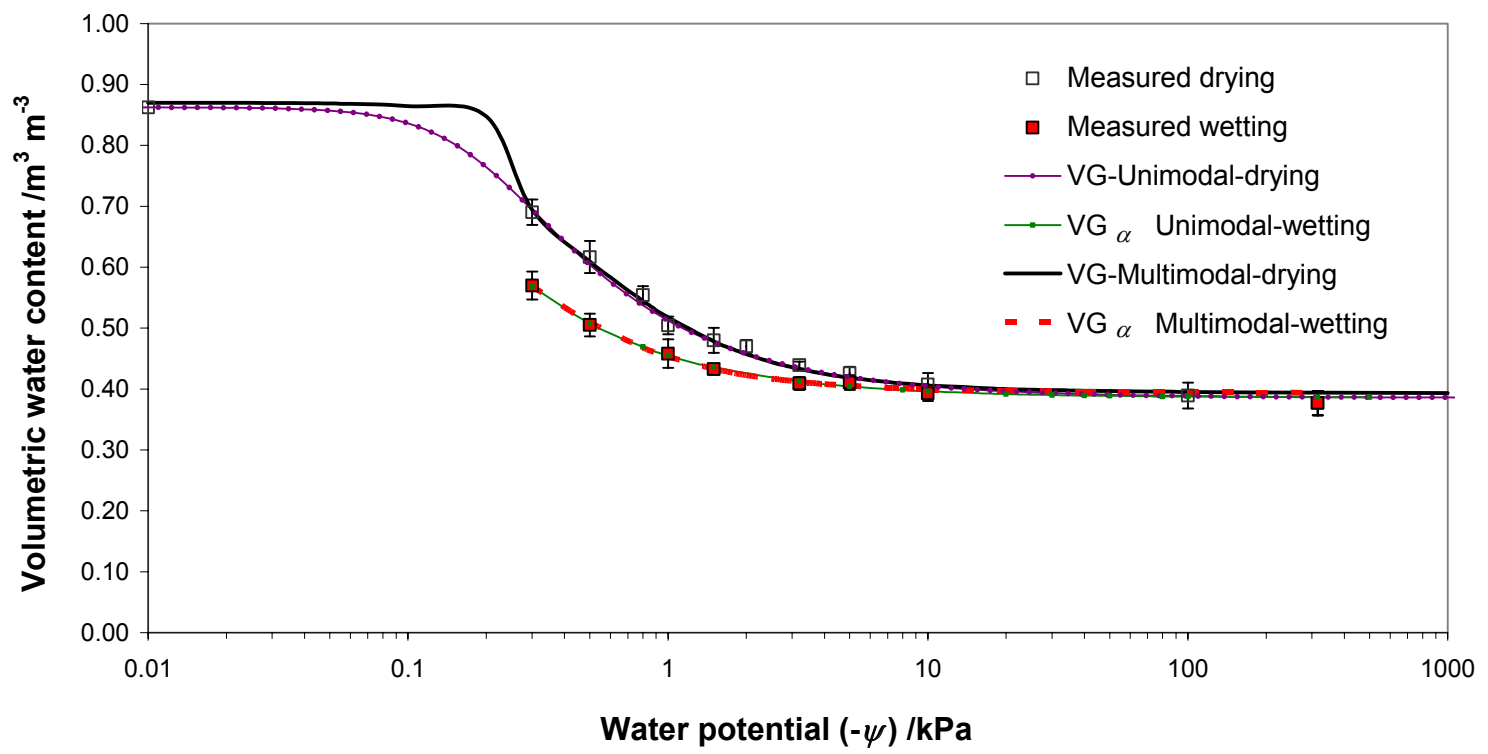

Fig. 2. Measured (symbols) and fitted (VG) water retention curves during drying (VG model) and wetting $\left(\mathrm{VG}_{\alpha}\right.$ model $)$ for pine bark. The bars indicate standard errors $(n=4)$. 


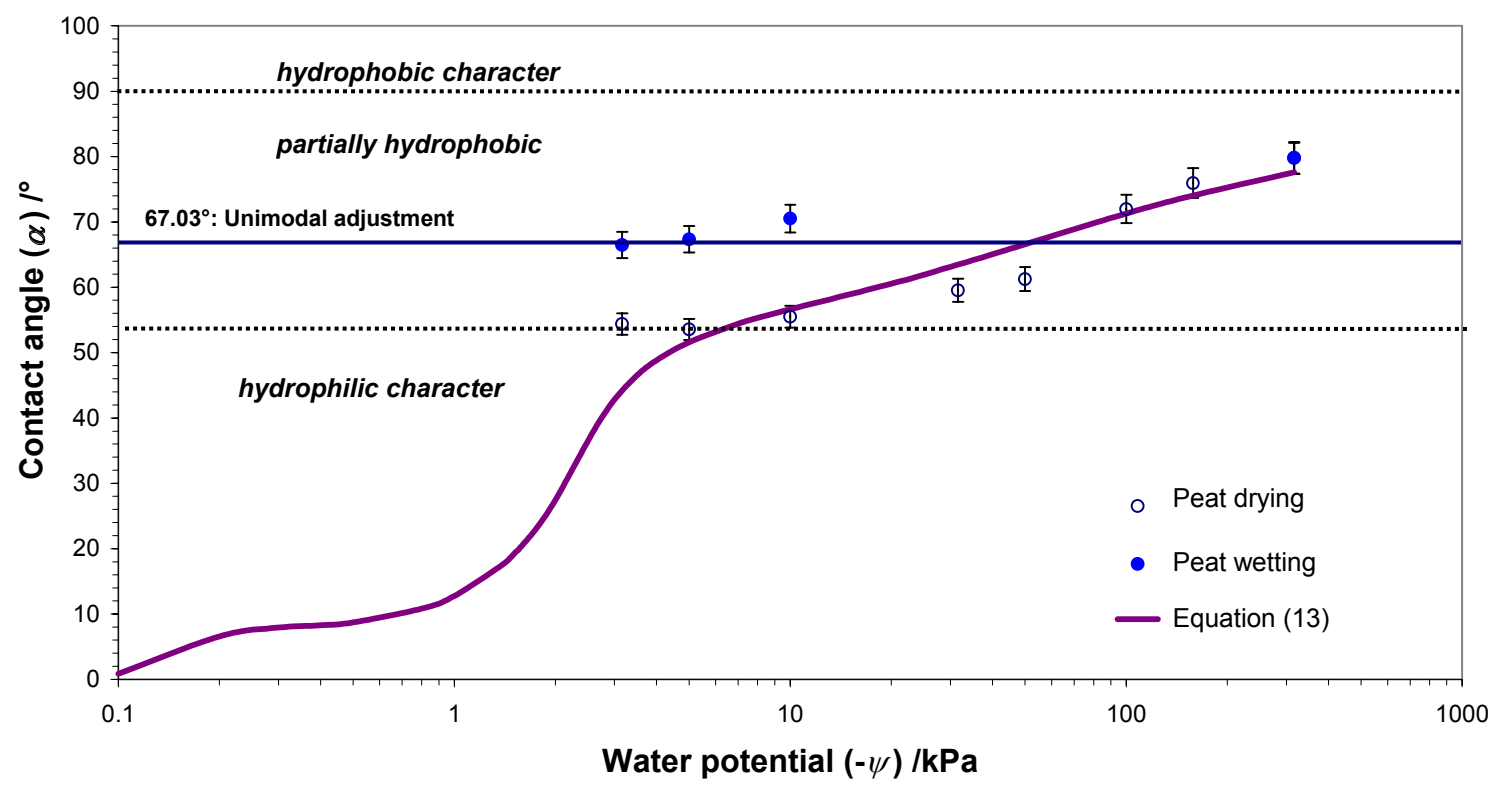

Fig. 3. Calculated (symbols) and simulated (with Equation 8) contact angles related to water potential during a drying/wetting cycle for peat. The bars indicate standard errors $(n=4)$.

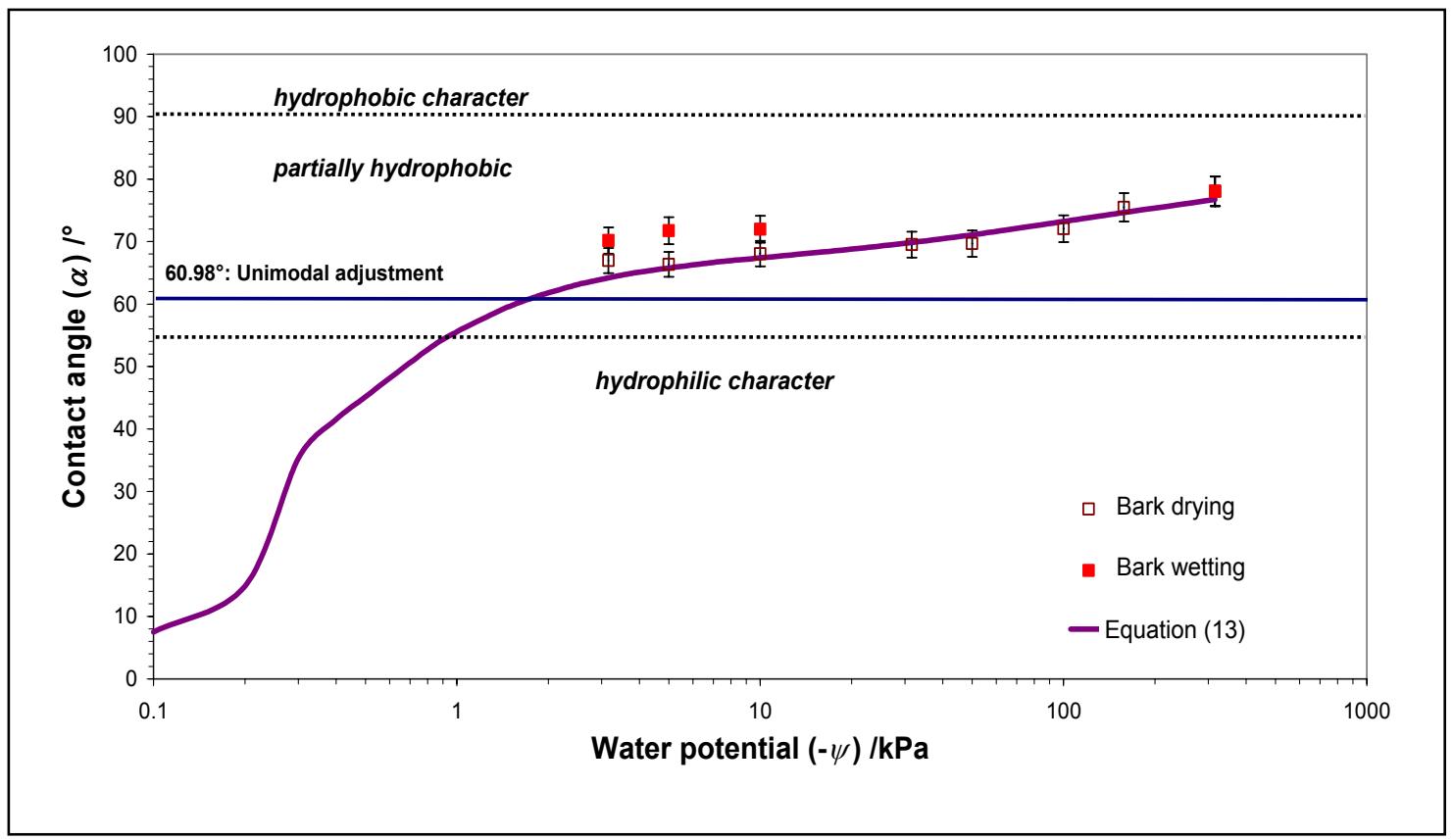

Fig. 4. Calculated (symbols) and simulated (with Equation 8) contact angles related to water potential during a drying/wetting cycle for pine bark. The bars indicate standard errors $(n=4)$. 
